\title{
Fine-scale prey aggregations and foraging ecology of humpback whales Megaptera novaeangliae
}

\author{
Elliott L. Hazen ${ }^{1, *}$, Ari S. Friedlaender ${ }^{1}$, Michael A. Thompson ${ }^{2}$, Colin R. Ware ${ }^{3}$, \\ Mason T. Weinrich ${ }^{4}$, Patrick N. Halpin ${ }^{1}$, David N. Wiley ${ }^{2}$ \\ ${ }^{1}$ Duke University Marine Lab, 135 Duke Marine Lab Rd., Beaufort, North Carolina 28516, USA \\ ${ }^{2}$ Stellwagen Bank National Marine Sanctuary, 175 Edward Foster Road, Scituate, Massachusetts 02066, USA \\ ${ }^{3}$ University of New Hampshire, 24 Colovos Road, Durham, New Hampshire 03824, USA \\ ${ }^{4}$ Whale Center of New England, 24 Harbor Loop, Gloucester, Massachusetts 01930, USA
}

\begin{abstract}
Analyses of the foraging behavior of large cetaceans have generally focused on either correlations with environmental conditions at regional scales or observations of surface behavior. We employed a novel approach combining multi-scale analyses of simultaneous environmental conditions, surface and subsurface humpback whale Megaptera novaeangliae movements, and sand lance Ammodytes spp. prey aggregations in the Gulf of Maine, USA. At the fine scale $(<1 \mathrm{~km})$, digital tags recorded whale movement and behavior in 3 dimensions. Concurrent synoptic prey data were collected using EK60 echosounders with simultaneous surface measurements of temperature and relative fluorescence within $1 \mathrm{~km}$ of the tagged whale. A geospatial analysis of environmental features and foraging patterns was conducted at the regional, seascape scale $(\sim 10 \mathrm{~km})$. At the seascape scale, we found: (1) a negative relationship between relative fluorescence and sand lance density; (2) a positive relationship between predator surface feeding, presumed sand lance density, and sand bottom types near high-slope edges; (3) a cyclical relationship for predator surface-feeding likelihood and prey density with tidal height; and (4) an observed temporal lag between peak prey density and predator surface-feeding likelihood. At the fine scale, we found that: (1) time of day was the most important factor in predicting whether a whale was feeding when it surfaced; and (2) surface feeding occurred more often around more dense, vertically distributed schools of prey. Multiscale and multitrophic level studies are an important component in understanding the foraging ecology of top predators in marine systems.
\end{abstract}

KEY WORDS: Predator-prey $\cdot$ Foraging ecology $\cdot$ Oceanography $\cdot$ Acoustics $\cdot$ Sand lance $\cdot$ Humpback whale $\cdot$ Telemetry tracking $\cdot$ Digital acoustic recording tag

\section{INTRODUCTION}

Foraging is comprised of several components: searching for, capturing, handling, and consuming prey. Optimal foraging theory predicts that an individual foraging on a prey patch should continue until the search time, capture, and handling of prey outweigh the net energetic gain from consumption (MacArthur \& Pianka 1966). When switching prey patches, predators must also take into account the potential value of future patches, they must consider the density and area of the current patch, and must include requisite search times for any new patches (the marginal value theorem: Charnov 1976). To date, field studies have been unable to determine the point at which a given prey patch becomes attractive to a consumer and have not identified the biological and physical cues predators use to find these energetically beneficial patches.

Baleen whales are marine predators that feed primarily on discrete patches of prey and presumably conform to optimal foraging theory. Foraging decisions encompass multiple scales from migration to feeding grounds (1000s of $\mathrm{km})$, the search for prey hotspots (100s of $\mathrm{km})$, to individual foraging events $(<10 \mathrm{~km}$, 
Kenney et al. 2001). In Witless Bay, Newfoundland, Piatt \& Methven (1992) used acoustic surveys for capelin Mallotus villosus concurrent with visual surveys of baleen whales to document a threshold limit of prey density below which foraging became unprofitable and whale aggregations did not occur. However, due to technological limitations, prey thresholds and foraging behaviors have rarely been examined for foraging at the scale of an individual whale $(<10 \mathrm{~km}$, Kenney et al. 2001).

Recent advances in archival tag technology provide the ability to recreate sub-surface movements and quantify behaviors in ways previously impossible for free-ranging cetaceans. Using a tag with 2-axis motion sensors, Goldbogen et al. (2006) documented feeding lunges in fin whales Balaenoptera physalus using changes in acceleration. When a fin whale opened its mouth to engulf prey, the drag led to an immediate deceleration. The 'DTag' (Johnson \& Tyack 2003) is a digital acoustic recording tag that has been used to visualize underwater behaviors. Because the tag provides precise measurements of depth and acceleration in 3 axes, researchers can detect individual fluke strokes and can quantify body orientations (e.g. Miller et al. 2004a, Ware et al. 2006).

It is difficult to obtain precise measurements of prey fishes in the marine environment. Measurements of the distribution of fish using net trawls are commonly used to correlate prey presence and density with the distribution and behavior of predators, but the spatial and temporal resolution provided by these techniques is coarse and prey species can vary in catchability (Harley \& Myers 2001). Fisheries acoustics offer a minimally invasive technique for collecting continuous along-track data on biomass at fine horizontal and vertical scales throughout the water column. By analyzing the amount of scattered sound returned to the transducer and sampling length frequency and species composition from net samples, backscatter can be used to estimate size of individual targets, density of schools, and overall abundance (Simmonds \& MacLennan 2005). In the absence of net sampling, acoustic backscatter can still be used as a valuable measure of relative density and abundance (Benoit-Bird et al. 2001). Acoustics have been used to observe changes in the distribution and behavior of fish such as herring school size and shape while feeding (Misund et al. 1998, Mackinson et al. 1999) and while under predation (Nøttestad et al. 2002).

To date, Croll et al. $(1998,2005)$ and Baumgartner et al. (2003) have completed some of the most integrated studies of individual baleen whale fine-scale foraging ecology. Croll et al. (2005) attached time-depth recorders (TDRs) to 2 blue whales Balaenoptera musculus and correlated the vertical profiles of their dives to the vertical distribution and density of euphausiid swarms in the area. Euphausiid density was approximately 2 orders of magnitude greater in areas where whales concentrated their presumed foraging effort than elsewhere in the study area (Croll et al. 2005). These investigators noted that 'as measurements of prey were directed at patches where whales were foraging, we feel that this provides, for the first time, an estimate of the magnitude of prey densities for large whales.' Baumgartner et al. (2003) used optical plankton counters and discrete-depth net tows to assess vertical and horizontal distribution of Stage V Calanus copepods while also surveying for North Atlantic right whales Eubalaena glacialis. Right whale abundance was greatest during the day near high concentrations of their preferred prey resource: deeper, diapausing C5 copepods (C. finmarchicus; $>90 \mathrm{~m}$ ).

Mayo \& Marx (1990) found significantly more prey in the path of skim-feeding North Atlantic right whales than in surrounding waters. Dolphin (1987) used qualitative sonar scans to describe the behavior of humpback whales Megaptera novaeangliae in Alaskan coastal waters that appeared to be foraging in the upper $120 \mathrm{~m}$ of the water column and associating with the shallowest and densest prey patches. An island wake eddy system led to dense prey aggregation and subsequently identified important foraging habitats of fin whales, minke whales Balaenoptera acutorostrata, and harbor porpoises Phocoena phocoena in the Bay of Fundy (Johnston et al. 2005a,b). While these studies analyzed correlatations between prey features and observations of foraging behavior, our inability to directly observe whale behaviors underwater has limited our ability to quantify and discriminate underwater foraging behavior relative to prey characteristics.

Humpback whales are cosmopolitan predators that typically feed seasonally in high latitude areas. Traditional foraging habitats maintain predictably high prey concentrations over time, and are often characterized by proximity to shore, dynamic bathymetry, upwelling, and increased productivity (Gaskin 1982, Piatt 1990, Thiele et al. 2004, Friedlaender et al. 2006). In the Gulf of Alaska, humpback whale dives were longer and deeper in the presence of prey (Witteveen et al. 2008), indicating deep feeding events. Deeper dives also occurred most often in proximity to high densities of capelin preferentially over other fish species in the area. For humpback whales, both the type of prey and its relative abundance over time contribute to habitat selection in the western North Atlantic (Whitehead \& Carscadden 1985, Payne et al. 1986, 1990, Weinrich et al. 1997, Stevick et al. 2006, 2008).

Stellwagen Bank in the Gulf of Maine is an important feeding site for humpback whales (Payne et al. 1990, Clapham et al. 1993, Weinrich 1998). Feeding 
behaviors include both deep-feeding and surfacefeeding foraging approaches. Deep-feeding whales often target prey horizontally distributed in the middle of the water column (e.g. Witteveen et al. 2008) or buried in the substrate (e.g. Hain et al. 1995, Friedlaender et al. 2009, this Theme Section). The surface-feeding strategies that these animals display on Stellwagen Bank are diverse, and include lunge feeding (Watkins \& Schevill 1979), bubble-feeding (Hain et al. 1982), lobtail feeding (Weinrich et al. 1992a), and other idiosyncratic feeding styles (Hays et al. 1985). These behaviors are suspected to facilitate feeding by aggregating or corralling prey. Feeding behavior is believed to vary by prey type, with many of these bubble-feeding behaviors used to catch sand lance Ammodytes spp., the dominant prey on Stellwagen Bank. The abundance of sand lance is in large part thought to drive the local abundance and distribution of humpbacks (Overholtz \& Nicolas 1979, Payne et al. 1990, Weinrich et al. 1997). However, humpback whales have also been observed feeding on Atlantic herring Clupea harengus, and krill (e.g. Meganyctiphanes spp.) in other regions of the Gulf of Maine including Cultivator Shoal (on Georges Bank), Jeffrey's Ledge, and Platts Bank (Anthony \& Waring 1980, Weinrich et al. 1997, Garrison 2000, Auster et al. 2001, Overholtz 2002). Research on foraging preferences can be used to understand the fine-scale distribution of humpback whales and to minimize exposure to anthropogenic threats in highly trafficked areas.

Stellwagen Bank contains specific substrates that are important habitat for American sand lance Ammodytes americanus and northern sand lance A. dubius (Auster et al. 2001). Bathymetric slopes around the bank serve to upwell nutrients, increasing primary productivity and ultimately zooplankton prey for sand lance (Robinson \& Lermusiaux 2002). As tidally driven waters pass over the shallow bank, turbulent flow creates internal waves that propagate along density gradients and can serve to aggregate zooplankton (Lennert-Cody \& Franks 1999, Warren et al. 2003, Stevick et al. 2008). In addition, bottom substrate on the bank includes the coarse-grained sandy habitat that sand lance use for burial and predator avoidance (Meyer et al. 1979). However the abundance of sand lance on and around Stellwagen Bank is ephemeral (Payne et al. 1990, Weinrich et al. 1997), possibly due to variation in climatic conditions, prey availability, and commercial fishing pressure on predators (Fogarty \& Murawski 1998, Garrison 2000) and/or competitors (Payne et al. 1990). Understanding the distribution of sand lance relative to their environment is an important step in understanding the pelagic food web on Stellwagen Bank.

Our goal was to combine acoustic measures of prey density with precise measures of whale movement and feeding behavior to test the following hypotheses regarding foraging humpback whales and their prey:

(1) Sand lance density is significantly correlated with increased bathymetric slope, relative fluorescence, and bottom type.

(2) Humpback whale surface-feeding events are correlated with increased bathymetric slope, relative fluorescence, and bottom type.

(3) Humpback whale surface-feeding events are correlated with increased prey density and school shape characteristics.

(4) Humpback whale surface-feeding events increase with prey density and show quantifiable foraging thresholds.

We believe this approach will allow us to elucidate the seascape-scale $(\sim 10 \mathrm{~km})$ and fine-scale $(<1 \mathrm{~km})$ foraging ecology of both predator and prey relative to environmental features.

\section{MATERIALS AND METHODS}

Data collection. Data were collected around Stellwagen Bank from 6 to 20 July 2006 with the goal of measuring environmental gradients, prey distribution, and predator behavior concurrently. The Bank is the focus of a $2181 \mathrm{~km}^{2}$ marine protected area located in the southwestern Gulf of Maine. The area is characterized by diverse topography, sediments, oceanographic conditions, and high primary productivity that result in abundant marine life, including humpback whales (Weinrich 1998, Stevick et al. 2008). The research was conducted from NOAA's RV 'Nancy Foster' (length = $60 \mathrm{~m})$ with tagging support from inflatable boats $(8 \mathrm{~m}$ or less) operating off the primary vessel.

Whale data: Whale behavior (e.g. surface feeding/ non-surface feeding) was inferred from tag records in combination with near continuous daytime focal surface observations. Tag attachment was accomplished using a $7 \mathrm{~m}$ rigid-hulled inflatable boat (RHIB) equipped with a $4 \mathrm{~m}$, bow-mounted, cantilevered carbon-fiber pole. The DTag is a small, lightweight, pressure-tolerant tag capable of recording data for approximately $24 \mathrm{~h}$ dependent on sampling frequency. It is attached to an animal via suction cups with a programmable release (Johnson \& Tyack 2003). The DTag measures the acceleration in the animal's pitch, roll, and heading, as well as depth at $50 \mathrm{~Hz}$. Data from the tag's pitch record allows for analysis of fluke stroke rates and relative stroke amplitudes and, combined with behavioral observation, allows the identification of surface-feeding bouts and quantification of their duration and maximum depth. All sensor data are stored in flash memory on the tag and are downloaded via an infrared connection to a computer for analysis. 
The tag has a VHF antenna that transmits when it is at the surface, allowing us to follow the whale both when it was out of visual range and at night. Additionally, the tag has 2 hydrophones that continuously record any sounds the animal either makes or experiences (Johnson \& Tyack 2003).

Focal follows of tagged animals and associates occurred continuously during daylight hours using techniques described by Whitehead (1983) and Weinrich \& Kuhlberg (1991). Whenever possible, the tagged animal's position was recorded using laser rangefinder binoculars (Leica Vector Viper II binoculars) with a realtime GPS data feed; these were combined to give the true position of the whale. When behavioral observations were unavailable (e.g. night), whale positions were estimated using the research vessel's location and relative proximity to the tagged whale as judged by the amplitude of VHF localized radio signals.

Prey sampling: Prey distribution and density were continuously measured using 38 and $120 \mathrm{kHz}$ SIMRAD EK60 echosounders towed off the vessel's port side Aframe at speeds between 2 and 5 knots depending on sea state and currents. Sampling frequency was 10 pulses $\mathrm{s}^{-1}$ and pulse widths were 512 and $256 \mathrm{~ms}$ for each frequency, respectively. Echosounders were calibrated before and after the cruise using a $23 \mathrm{~mm}$ copper sphere and target strength values of -48.0 and $-40.4 \mathrm{~dB}$ for 38 and $120 \mathrm{kHz}$, respectively (Demer et al. 1999). Acoustics data were also collected in the absence of whales and treated as a control measure of prey density.

Sampling scale is a concern in ecological experiments, as predators and prey perceive and respond to their surroundings at a range of scales (Fauchald et al. 2000). We attempted to resolve prey distribution and predator behavior at similar scales, as there is no single scale correct for studying ecological relationships (Levin 1992). Depending on the behavior of the tagged whale, an iterative approach to sampling prey was employed. If the whale was traveling $\left(>1 \mathrm{~km} \mathrm{~h}^{-1}\right.$ displacement), a zig-zag design was used to survey prey distributions passed over by the whale $(1.5 \mathrm{~km}$ transects centered on the whale's position). Surface feeding (which includes lunge and bubble feeding) was identified by observing the animal with its mouth gaped or when bubbles were located where the animal surfaced. If the tagged whale was surface feeding, an expanding box sampling design allowed the measurement of prey density and distribution at varying scales, with the center of the sampling box moving with the whale. This approach was designed to measure multiple prey patches: before the feeding whale had visited them, after they had been visited, and while they were being visited. In practice, our smallest sampling box was $1 \mathrm{~km}^{2}$. The expanding square was designed to measure patches surrounding the foraging whale before and after feeding events. The sampling design around stationary and non-feeding whales was identical, with an expanding box to examine the prey distribution surrounding the tagged whale. As a result, our design allowed us to quantify the distribution and density of prey patches in a variety of locations in the sanctuary from both feeding and non-feeding whales.

When measuring prey and environmental data relative to surfacing events, transects were designed to pass within $200 \mathrm{~m}$ of a tagged whale. For each whale surfacing, correlations between whale behavior, prey data, and environmental data were only considered within a $500 \mathrm{~m}$ radius. All visual observations of prey in the presence of feeding whales during the survey were identified as sand lance, including photos of prey in the gaped mouth of foraging whales and photos of schools at the surface. In addition to visual identification, we compared the data at 120 and $38 \mathrm{kHz}$ to categorize acoustic targets and schools as non-swimbladdered fish (e.g. sand lance) due to frequency-dependent scattering (Freeman et al. 2004, Gauthier \& Horne 2004). Without net tows we cannot definitively state that all acoustic targets were sand lance, but our visual and acoustic identification techniques supported our assumption.

Oceanographic data: Environmental and physical data were collected using continuous shipboard measurements of relative surface fluorescence and surface temperature concurrent with prey acoustics. Existing bathymetric multibeam and bottom typing data sets were incorporated in our surface feeding and prey models. Areas of high bathymetric gradient were defined by slope (top quartile) and were used to create the distance from slope layer. CTD casts measuring salinity, dissolved oxygen, temperature, and fluorescence were performed at the time and location when a whale was tagged, and when the tag detached, as well as every 2 to $3 \mathrm{~h}$ during tag deployment. Real-time surface temperature and relative fluorescence were collected through an uncontaminated seawater system on the bow and measured using a SeaBird SBE 38 with a fluorometer. Tidal height was measured by NOAA in Boston Harbor (approximately $55 \mathrm{~km}$ from the study site). Day length was defined as the time between sunrise and sunset, as identified from NOAA's marine weather database.

Data analysis. Behavioral data from tagged whales were integrated with physical data and measurements of prey patch distribution, density, and shape collected during the synoptic acoustic surveys.

Prey sampling: Acoustic data provided a relative measure of patch density in logarithmic units of decibels (dB). Acoustic data were processed using Sonar- 
data Echoview software (version 4.20). The sounderdetected bottom was manually rectified, and all data within $50 \mathrm{~cm}$ from the bottom were excluded from analysis. Individual schools were marked, visually scrutinized, and integrated, and school parameters were exported to text files using the SHAPES school detection algorithm (5 m linking distance) for 38 and $120 \mathrm{kHz}$ data incorporating a $-75 \mathrm{~dB}$ threshold (Coetzee 2000). To examine overall water column biomass, acoustic backscatter was vertically integrated into the nautical area scattering coefficient (NASC; $\mathrm{m}^{2}$ $\mathrm{n}$ mile $\mathrm{e}^{-2}$ ), a relative measure of biomass. Mean volume backscatter strength (MVBS), a relative measure of density, was subsequently gridded into $50 \mathrm{~m}$ horizontal cells by $1 \mathrm{~m}$ vertical cells with a $-90 \mathrm{~dB}$ threshold to examine smaller prey aggregations. We chose $50 \mathrm{~m}$, as this was the mean size of prey schools that we observed. We refer to MVBS as either backscatter or prey density throughout this paper. All exported acoustic biomass data including geo-referenced 2D school parameters (density, length, mean height, mean depth), integrated cell biomass (density per $50 \mathrm{~m}$ ), and bottom depth were imported into ESRI's ArcGIS 9.2 for spatial analysis.

Whale data: We combined the pitch, roll, heading, and depth data from the DTag with whale surfacing locations to generate a geo-referenced 'pseudo-track' of each animal's movements. We use the term 'pseudotrack' to identify that the exact track of the whale is unknown. The main error is a result of the tag's inability to resolve swim speeds, which likely vary during different parts of each dive. The pseudo-track was then incorporated into Trackplot, a customized visualization software package that allows for examination of temporally sequenced behaviors as spatial patterns (Ware et al. 2006). The program creates a 3D ribbon indicating the whale's depth, direction of travel, body orientation (pitch and roll) and fluke strokes. To visualize certain behaviors, like rolling, the ribbon incorporates sensor data and twists around the along-track heading (Ware et al. 2006).

We then coded every surfacing from each tagged whale as either a surface-feeding or non-surface-feeding event, based on the behavioral observations during focal follows. We did not include deep feeding or bottom feeding as a separate behavioral type because there were too few samples for our analyses. After a preliminary examination of time-linked surfacing observations from the behavioral data and Trackplot visualizations, we were able to define underwater movement patterns that resulted in a surface-feeding event. The duration of a feeding event was defined from the start of the dive encompassing a feeding event to the end of the dive when the animal re-surfaced. When individuals made multiple loops (e.g. kick feeding) before the final surfacing, the entire behavior was coded into a single feeding event. The mean depth of feeding events and total dive duration per feeding event were quantified using Trackplot and compared to prey distribution. Surface feeding was identified from the tag record using dive and ascent angles $\left(>45^{\circ}\right.$ head down or head up), roll angles $\left(>45^{\circ}\right.$ fluke off axis), and incorporated between 1 and 3 individually stereotyped vertical loops. In a blind comparison using a subset of data, we were able to successfully code surface-feeding events in Trackplot validated against behavioral observations $97 \%$ of the time ( $\mathrm{n}=100$ events). Thus, in the absence of behavioral data (e.g. at night), the iterative process gave us confidence in behaviors identified by analysis using Trackplot. Locations of surface-feeding and non-feeding surfacing event locations were then imported into ArcGIS.

Data sampling and statistics: In order to sample data for each behavioral event, fish school parameters (length, height, area, density, depth), logarithmic measures of acoustic density (dB), surface temperature $\left({ }^{\circ} \mathrm{C}\right)$, and relative fluorescence $(\mathrm{V})$ were interpolated into temporally distinct raster grid cells using an ordinary kriging function while adjusting variograms to minimize root mean square (RMS) error of the weighted least square models (Petitgas 1993, Maravelias et al. 1996). Additional existing physical layers (distance to slope, bottom depth, bottom type) were also included in our sampling. Tidal height was temporally linked to each data point. Each sighting following a surface foraging or non-foraging event was used to sample interpolated environmental and school parameters when measured within $500 \mathrm{~m}$. If environmental and prey data were unavailable within $500 \mathrm{~m}$ from the sighting, the surfacing was not used in our analyses. We chose $500 \mathrm{~m}$ because it was the maximum distance observed between subsequent surface feeding events. The resultant samples were imported into Insightful's S-Plus 7.2 for statistical analysis.

For prey data, generalized additive models (GAMs) were used to examine the non-linear relationship between prey density and environmental variables using a Gaussian distribution. A generalized linear model (GLM) was used to examine the linear effects of each environmental variable on prey density. To examine thresholds in predator behavior, a classification and regression tree (CART; Redfern et al. 2006) analysis was conducted with whale behavior (surface feeding/other) as a binomial response variable with 24 environmental and prey variables as predictors. Optimal recursive partitioning combined with a cross-validation using explained deviance ensured that only the most significant breaks were included in the final model. Generalized additive mixed models (GAMMs) were then used to examine the non-linear relationship 
between CART-selected variables and whale foraging behavior using a binomial distribution to test for significant effects (Wood 2006). The model included each tagged whale as a random term with each surfacing event nested within the individual whale. We also examined foraging dive depths with mean prey school depth to look for correlation in behavior.

\section{RESULTS}

We detected 2980 fish schools from the $120 \mathrm{kHz}$ acoustic data. We present results for $120 \mathrm{kHz}$ data only, because models with both frequencies found no significance from $38 \mathrm{kHz}$ measures (density, patch size, and shape) when $120 \mathrm{kHz}$ variables were included. Prey biomass was patchily distributed with the NASC varying 3 orders of magnitude from 2000 to $2 \mathrm{~m}^{2} \mathrm{n}$ mile $\mathrm{e}^{-2}$ as small as $200 \mathrm{~m}$ apart (Fig. 1). Measured schools spanned up to $4 \mathrm{~km}$ horizontally with vertical heights up to $30 \mathrm{~m}$. Detected schools had an average density of $-57.7 \mathrm{~dB}$ with a range from -72.9 to $-33.1 \mathrm{~dB}$. The mean school length was $139 \mathrm{~m}$ and the mean height was $7.9 \mathrm{~m}$. While most of the survey effort was concen- trated near the western edge of the bank due to the distribution of whales, prey density was greatest near high bathymetry gradients along the western bank edge (Fig. 1).

DTags were deployed on 15 individual humpback whales, and we collected $95 \mathrm{~h}$ of data from tagged whales: $66 \mathrm{~h}$ during daytime and $29 \mathrm{~h}$ at night (Fig. 2; see Friedlaender et al. 2009 for tag durations). Eleven of the $15(73.3 \%)$ tagged whales were visually observed surface feeding for a total of 393 of the 892 surfacings $(44.0 \%)$. Whale behavior was not visibly affected by the tagging event for any of the tagged whales. This is not surprising, as humpback whales showed no significant change in behavior (other than immediate startle responses) after biopsy sampling procedures in the great majority of cases (Weinrich \& Kuhlberg 1991, Weinrich et al. 1992b, Clapham et al. 1993). Right whales also showed a return to normal behavior after 2 dive cycles following a tagging event (Nowacek et al. 2004). Our descriptive results focus on the behavior of an individual whale that showed multiple behavioral switches and was representative of the overall dataset.

Examining the longest tag deployment (Whale 196a, $\sim 21.5 \mathrm{~h}$ ), surface foraging bouts occurred at 3 distinct

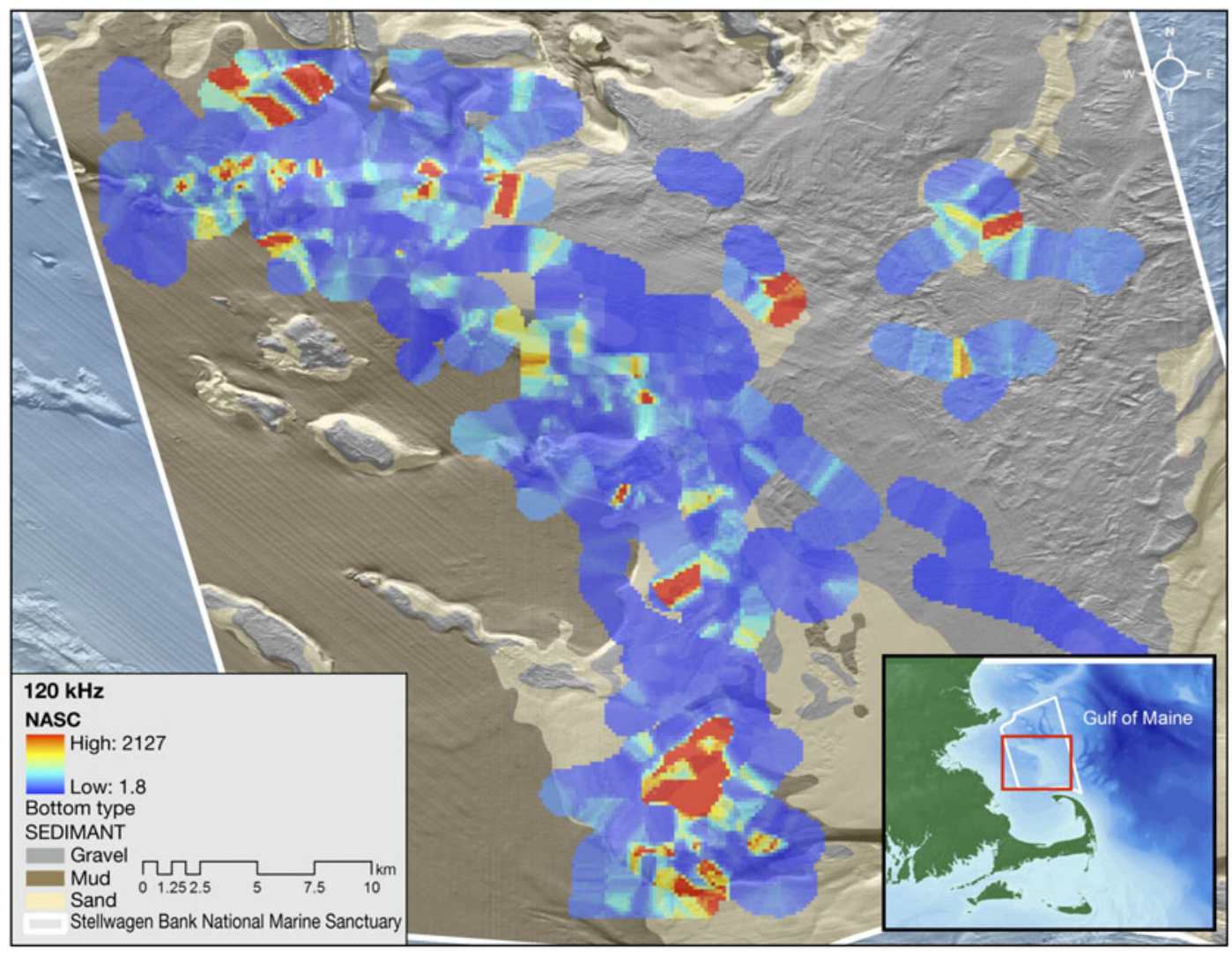

Fig. 1. Study area (Stellwagen Bank National Marine Sanctuary) is shown as a white outline in the subset image with land represented as green. Red rectangle in the subset shows the scale of the larger image. EK60 echosounder-measured vertically integrated prey density (nautical area scattering coefficient, $\mathrm{NASC}_{;} \mathrm{m}^{2} \mathrm{n}$ mile $\mathrm{e}^{-2}$ ) was interpolated within $1 \mathrm{~km}$ of the ship track every $12 \mathrm{~h}$. Red (blue) represents high (low) relative density 


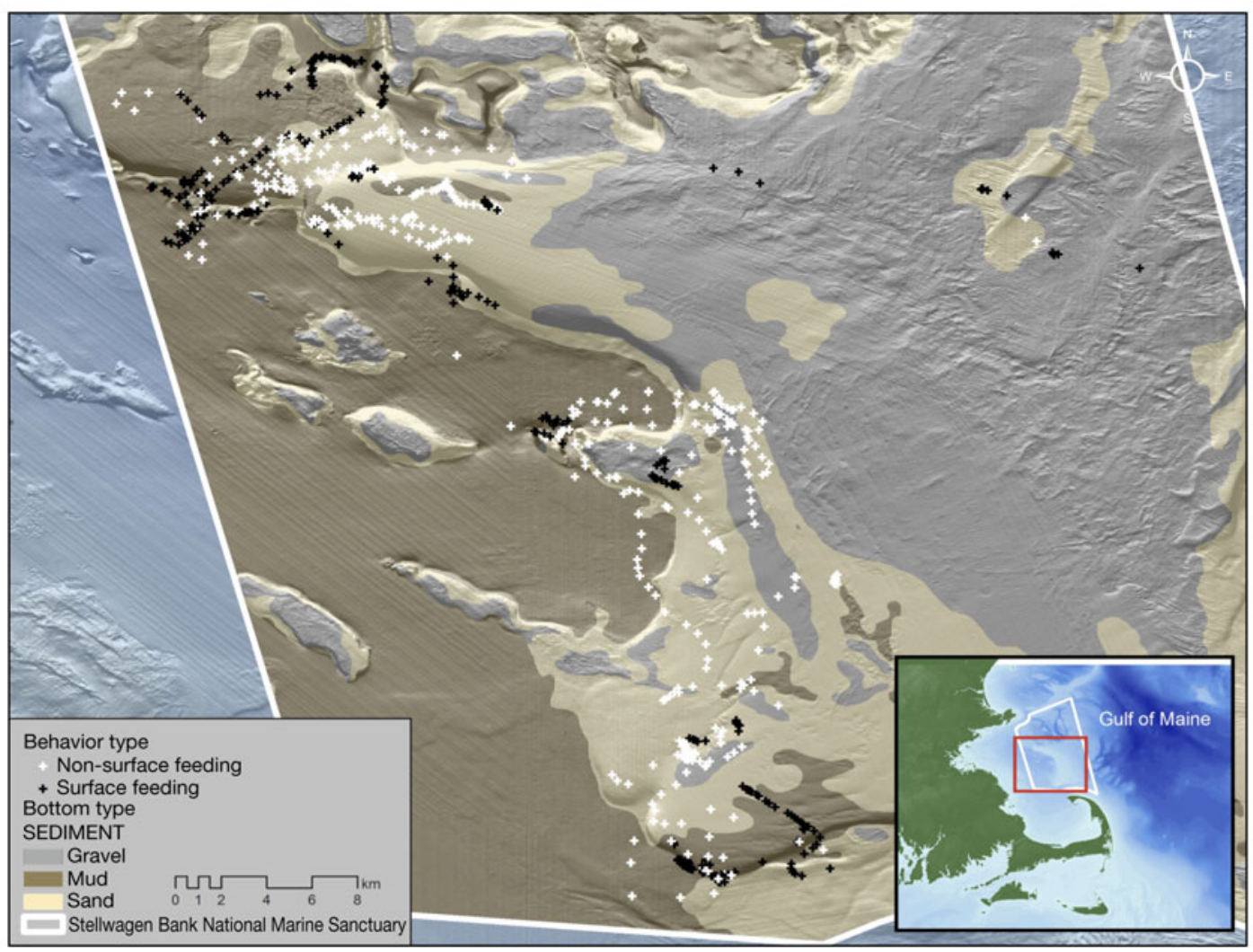

Fig. 2. On the main image, digital acoustic recording tag (DTag)-measured surface-feeding events are shown in black with nonfeeding surfacings shown in white for all 15 whales tagged. Bottom type is represented with dark brown for mud, light brown for sand, and gray for gravel

times and locations (Fig. 3). The whale was surface feeding when the tag was attached at 08:51 $\mathrm{h}$ and stopped at 10:00 h. Surface feeding commenced again at 19:00 $\mathrm{h}$ and continued until 20:16 h. The final feeding bout began at 05:00 $\mathrm{h}$ the next morning and continued until the tag released at 06:30 $\mathrm{h}$. During the tag deployment, 153 surfacings were recorded from visual observation, with 40 classified as surface-feeding events. For example, during the first feeding bout, Whale 196a was observed lobtailing followed by a feeding event in a bubble net in $66 \mathrm{~m}$ of water. This behavior is shown in the whale track (Fig. 4a) with a corresponding prey school. Large surface schools were visible in the acoustic data recorded simultaneously with the feeding events. On a broader scale, 2 out of 3 of the surface-feeding bouts overlapped with high prey density areas while the third was about $1 \mathrm{~km}$ from the nearest recorded high density patch. However, a regression of surface-feeding depth against mean prey school depth had a low $\mathrm{R}^{2}$ value $(0.11)$ with high variability in the non-significant relationship.

We found that all of our measured environmental variables had significant, non-linear effects on prey density ( $p<0.05$; Table 1$)$. However, time, temperature, and bottom depth explained $82 \%$ of the variabil- ity in the model of prey density. Prey density in the water column was greatest from 03:30 to 05:30 $\mathrm{h}$ with a decline at 17:00 $\mathrm{h}$ and lowest after 20:00 h (Fig. 5). We also observed a large amount of biomass on the shallow shelf with a peak in biomass at $20 \mathrm{~m}$ depth. There was a negative relationship between backscatter and depth from 20 to $35 \mathrm{~m}$ switching to a positive relationship between backscatter and depth from 35 to $100 \mathrm{~m}$. We found a negative relationship between backscatter and relative fluorescence. There was a greater amount of fish biomass near areas of high bathymetric relief, such as the bank edge. Prey were found in greatest density over bottom types of sand and mud with lower density in the water column above gravel. There was a cyclical relationship with tidal height as well with a peak in prey density at $\sim 2.4 \mathrm{~m}$ tidal height. At lower and higher tidal values, prey density showed a decline.

The CART analysis (Fig. 6) revealed a number of thresholds that were predictors of whale surface feeding. A pronounced diel component was identified, with surface feeding not detected after 20:29 h or before 04:40 h. In addition, an inverse relationship with fluorescence emerged. At low relative fluorescence levels $(<0.06 \mathrm{~V}), 163$ out of 192 surfacings were feeding events. When tidal height was greater than $7.3 \mathrm{~m}$ or 


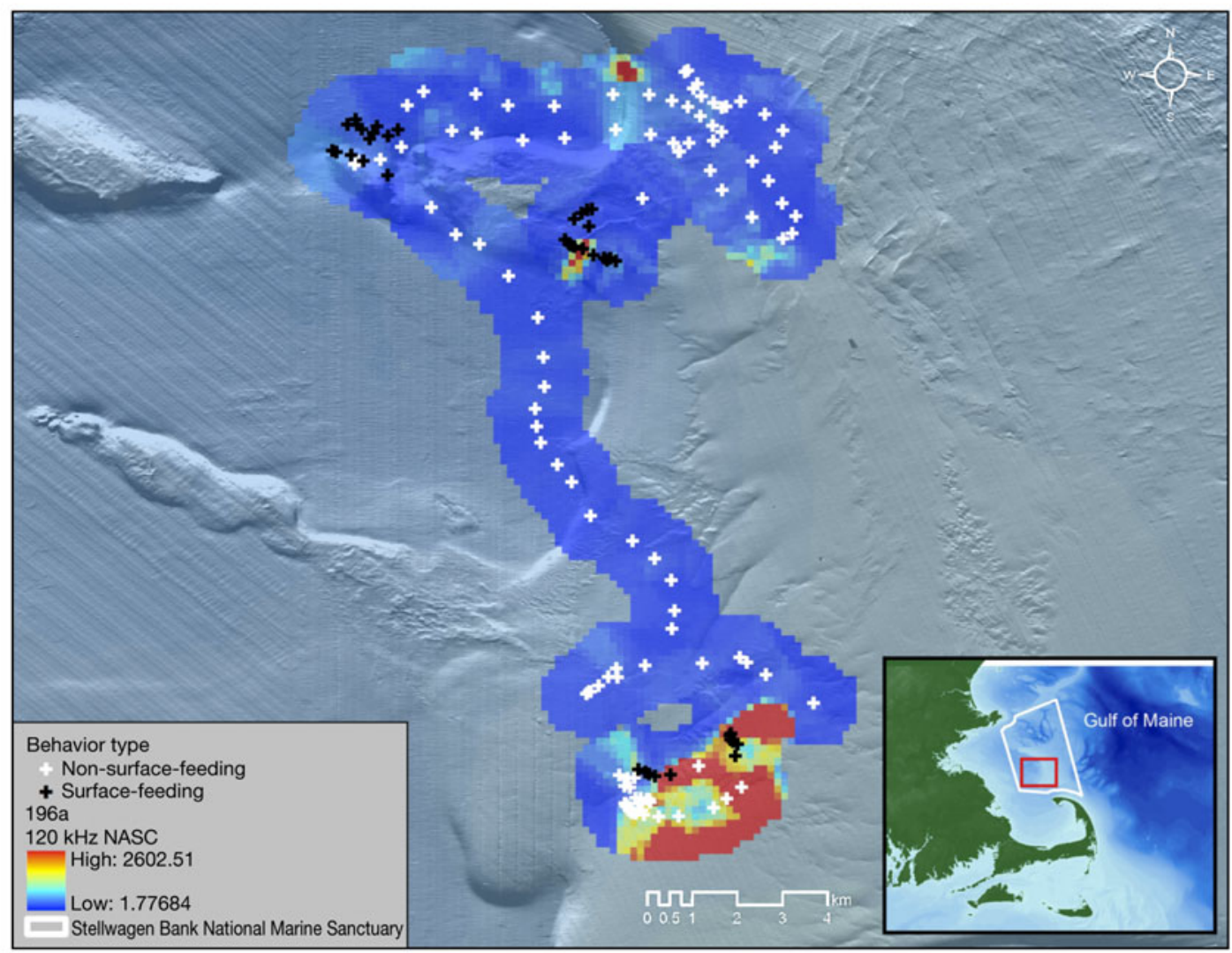

Fig. 3. Individual whale track in the southwest corner of the sanctuary for Whale 196a, from 09:00 h on 15 July to 06:00 h on $16 \mathrm{July}$. Interpolated vertically integrated prey density (nautical area scattering coeeficient, NASC; $\mathrm{m}^{2} \mathrm{n}$ mile ${ }^{-2}$ ) is shown with high (low) vertically integrated backscatter in red (blue). Red rectangle in the subset shows the scale of the larger image

observations were close to the slope, whales were also more likely to be surface feeding. At higher fluorescence levels, high tide height (>1.91 m), shallow school height $(<12 \mathrm{~m})$, and high prey density $(>-65.3 \mathrm{~dB})$ were correlated with surface feeding events.

GAMM output showed that temperature, bottom depth, and school depth were the only variables that did not have a significant effect on the likelihood of whale surface feeding for any given surfacing (Table 2). Time, tidal height, relative fluorescence, and prey density explained the largest amount of deviance in the feeding model. Whale feeding showed a peak around 07:00 $\mathrm{h}$ and began to decline around 18:00 h, peaking $2 \mathrm{~h}$ after prey density was greatest (Fig. 7). Whale feeding behavior increased in likelihood at high tidal heights $(4 \mathrm{~m})$ with a peak at $9 \mathrm{~m}$. Surface feeding behavior was more likely to take place over mud and sand bottoms when compared to a gravel substrate, and there was a notable decline in feeding behavior as relative fluorescence increased. Surface feeding was observed more often over deeper water depths and close to the slope edge. For the prey school parameters, a large increase in surface-feeding likelihood occurred up to $-63 \mathrm{~dB}$ with a less steep increase with higher backscatter values. There was a positive relationship between whale surface-feeding behavior and both prey school height and area. However, there was a negative relationship between whale surface feeding and mean prey school depth and length (e.g. horizontal size) in the water column. These results are useful in elucidating potential foraging thresholds as well as identifying environmental variables that could influence humpback whale foraging behavior.

\section{DISCUSSION}

While synoptic surveys of environmental variables, prey distribution, and predator behavior can be difficult to align across temporal and spatial scales, such approaches are required to understand the foraging ecology of marine predators. Recent technological advances in high-frequency prey detection capabilities have made such multidisciplinary studies more feasible, especially at fine scales. By using hydroacoustic measurements of prey, real-time sensors for oceanographic variables, and measurements of the fine-scale behavior of predators, we were able to examine factors 

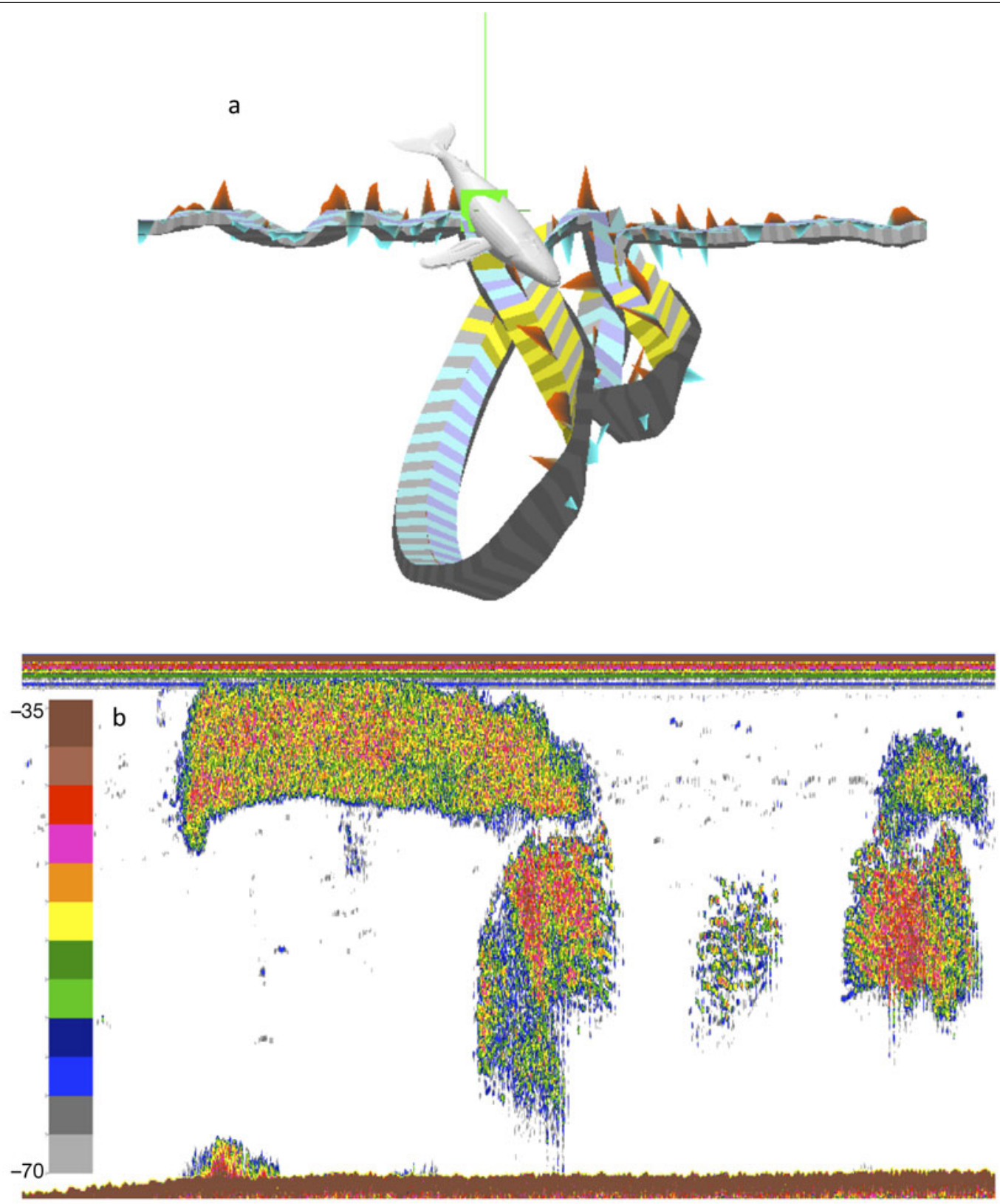

Fig. 4. (a) Trackplot image of Whale 196a at 09:27 h beginning a characteristic double loop. Behavioral sequencers observed a lobtail and bubble net during this dive. (b) At 09:24 h, a large prey patch was observed in the water column in $66 \mathrm{~m}$ of water.

Red (blue) represents high (low) relative density $(\mathrm{dB})$

Table 1. Generalized additive model (GAM) results for areal backscatter (nautical area scattering coefficient) as linear and nonlinear relationships of environmental variables. Significant p-values $(<0.05)$ are shown in bold. M: mud; S: sand; G: gravel. N/A: not applicable

\begin{tabular}{|c|c|c|c|c|c|c|}
\hline \multirow{2}{*}{ Parameter } & \multicolumn{3}{|c|}{ Linear effects } & \multicolumn{3}{|c|}{-Nonlinear effects } \\
\hline & $\mathrm{df}$ & $\chi^{2}$ & $\mathrm{p}$ & df & $F$ & $\mathrm{p}$ \\
\hline Time & 1 & 23427.52 & $<0.001$ & 3 & 82.07 & $<0.001$ \\
\hline Tidal height (m) & 1 & 21815.59 & $<0.001$ & 3 & 16.85 & $<0.001$ \\
\hline Bottom type (M/S/G) & 2 & 23139.42 & $<0.001$ & N/A & N/A & N/A \\
\hline Temperature $\left({ }^{\circ} \mathrm{C}\right)$ & 1 & 23397.27 & 0.057 & 3 & 37.01 & $<0.001$ \\
\hline Relative fluorescence & 1 & 23396.49 & 0.377 & 3 & 9.65 & $2.35 \times 10^{-6}$ \\
\hline Distance to slope (m) & 1 & 23288.42 & $<0.001$ & 3 & 4.82 & 0.0023 \\
\hline Bottom depth $(\mathrm{m})$ & 1 & 23400.89 & $<0.001$ & 3 & 30.01 & $<0.001$ \\
\hline
\end{tabular}



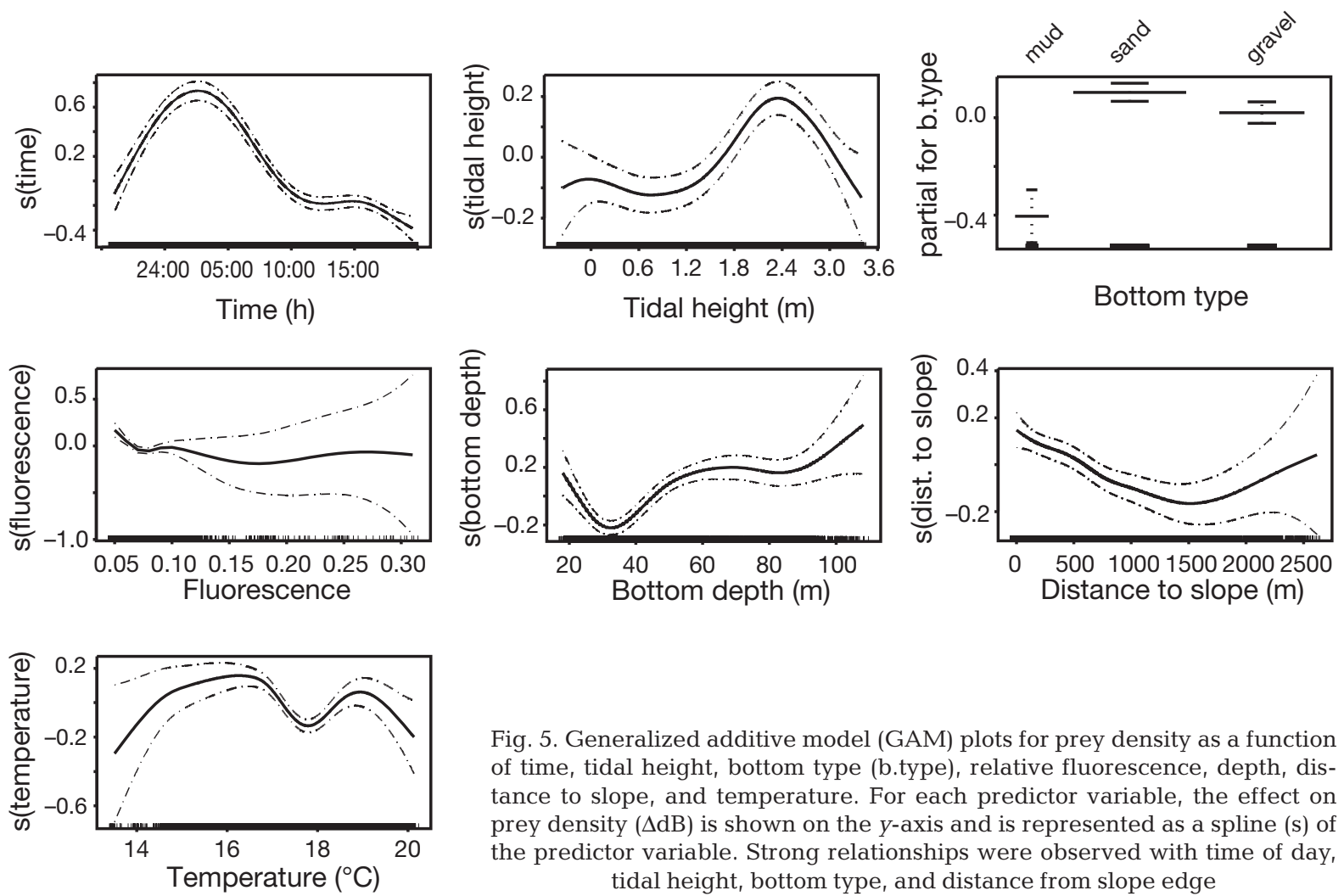

Fig. 5. Generalized additive model (GAM) plots for prey density as a function of time, tidal height, bottom type (b.type), relative fluorescence, depth, distance to slope, and temperature. For each predictor variable, the effect on prey density $(\Delta \mathrm{dB})$ is shown on the $y$-axis and is represented as a spline (s) of the predictor variable. Strong relationships were observed with time of day, tidal height, bottom type, and distance from slope edge

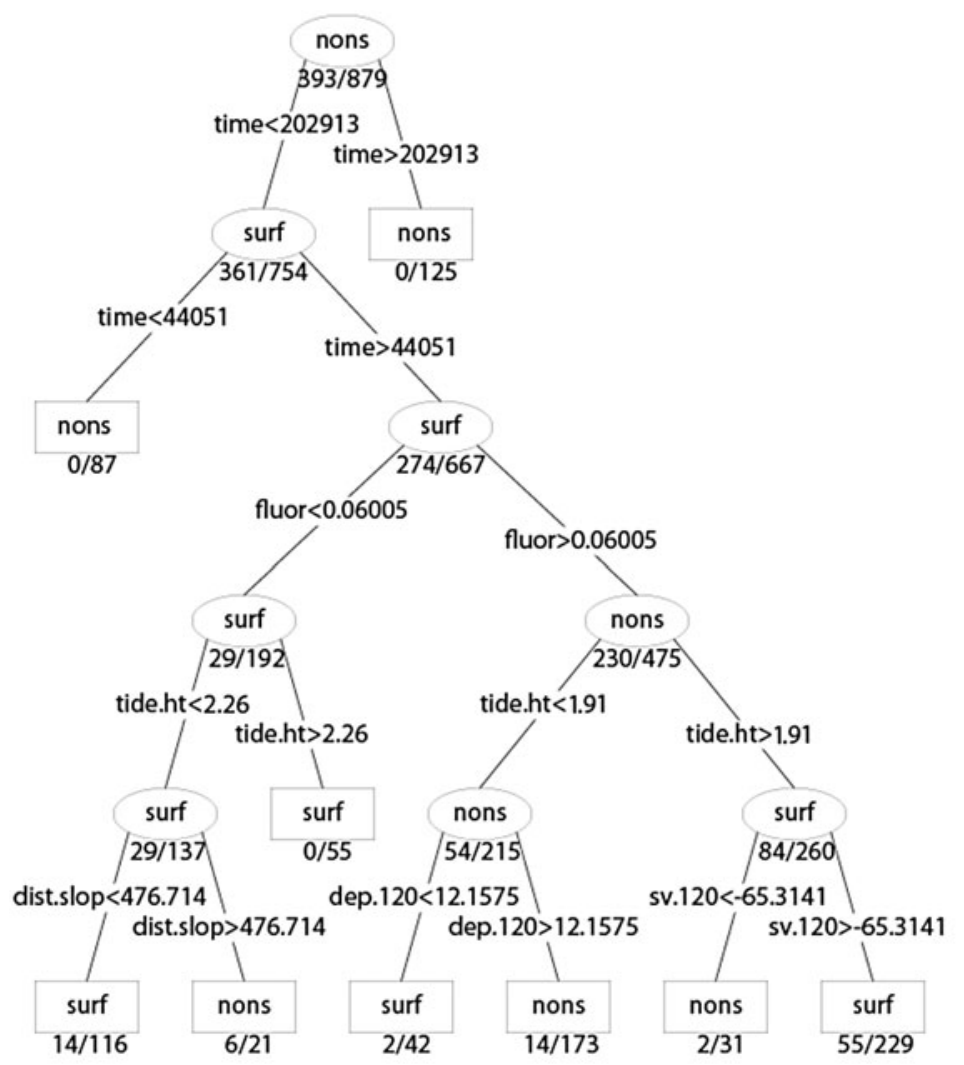

that influence multiple humpback whale surface feeding at both seascape and fine scales. At basin-wide scales, recent work suggests that the highest densities of humpback whales in the Gulf of Maine occur primarily along a relatively narrow corridor following the $100 \mathrm{~m}$ isobath (Pittman et al. 2006). Our results suggest that on a finer scale, a mixture of temporal effects, environmental effects, and dynamic prey distribution affects the whales' behavior and likely their distribution. At the seascape scale, we found a high correlation between prey density and the measured environmental variables, while humpback whale surface-feeding events on a fine scale were best correlated with prey school

Fig. 6. Classification and regression tree (CART) for behavioral state of tagged humpback whales: surface feeding ('surf') or not surface feeding ('nons'). Breaks were chosen based on deviance explained with values shown on each branch of the tree. Numbers below each terminal node represent the number of misclassified observations out of the total number of observations. Time of day was the most definitive split for surface foraging and non-surface foraging behaviors. See Fig. 5 for abbreviations and measurements 
Table 2. Generalized additive mixed model (GAMM) results for likelihood of whale surface feeding as linear and non-linear relationships of school parameters and environmental variables. Significant p-values $(<0.05)$ are shown in bold. Pr: probability; M: mud; S: sand; G: gravel. N/A: not applicable

\begin{tabular}{|c|c|c|c|c|c|c|}
\hline \multirow{2}{*}{ Parameter } & \multicolumn{3}{|c|}{ Linear effects } & \multicolumn{3}{|c|}{ - Nonlinear effects } \\
\hline & $\mathrm{df}$ & $\chi^{2}$ & $\operatorname{Pr}\left(\chi^{2}\right)$ & $\mathrm{df}$ & $F$ & $\operatorname{Pr}(F)$ \\
\hline Time & 1 & 214.32 & 0.174 & 3 & 32.73 & $<0.001$ \\
\hline Tidal height (m) & 1 & 205.07 & 0.002 & 3 & 14.17 & $<0.001$ \\
\hline Bottom type (M/S/G) & 2 & 190.39 & 0.001 & N/A & N/A & N/A \\
\hline Temperature $\left({ }^{\circ} \mathrm{C}\right)$ & 1 & 157.49 & 0.106 & 3 & 1.62 & 0.183 \\
\hline Relative fluorescence & 1 & 173.05 & $<0.001$ & 3 & 9.13 & $<0.001$ \\
\hline Distance to slope (m) & 1 & 160.10 & 0.007 & 3 & 3.64 & 0.013 \\
\hline Bottom depth (m) & 1 & 167.28 & 0.016 & 3 & 0.95 & 0.418 \\
\hline School density (dB) & 1 & 148.45 & 0.003 & 3 & 6.21 & $<0.001$ \\
\hline School area $\left(\mathrm{m}^{2}\right)$ & 1 & 140.42 & 0.005 & 3 & 4.22 & 0.006 \\
\hline School height (m) & 1 & 137.71 & 0.100 & 3 & 2.78 & 0.040 \\
\hline School depth (m) & 1 & 134.94 & 0.096 & 3 & 1.83 & 0.141 \\
\hline School length (m) & 1 & 97.02 & 0.295 & 3 & 2.76 & 0.041 \\
\hline Individual whale & 14 & 69.15 & 0.090 & N/A & N/A & N/A \\
\hline
\end{tabular}

shape and density, as well as the above-mentioned environmental variables.

Although split-beam acoustics only measures an instantaneous vertical profile in the water column, we were able to use continuous recording to describe the along-transect 2-dimensional patch shape and density of sand lance schools on Stellwagen Bank relative to foraging whales. Prey distribution was best predicted by time of day, corroborating previous studies of sand lance behavior. Adult sand lance are thought to be pre-
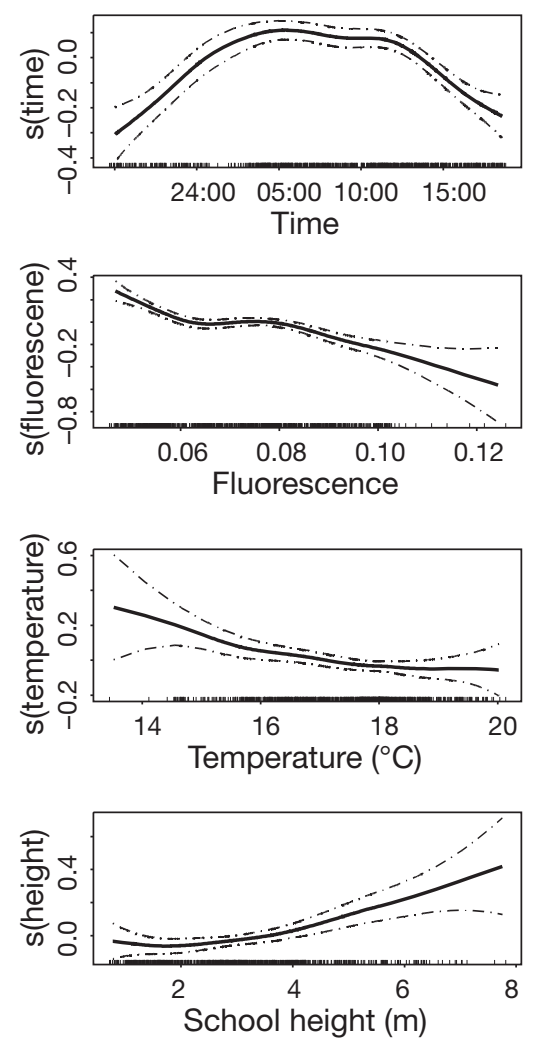
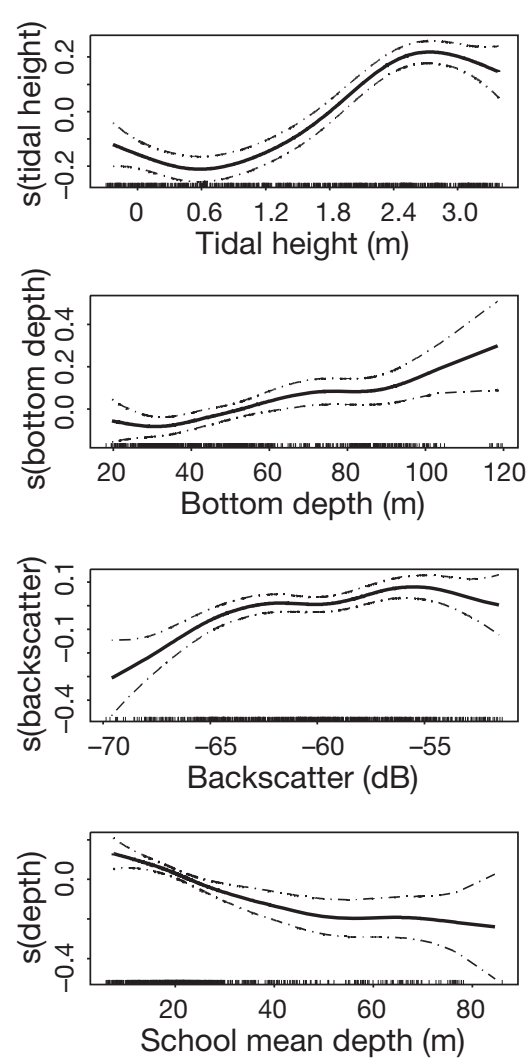
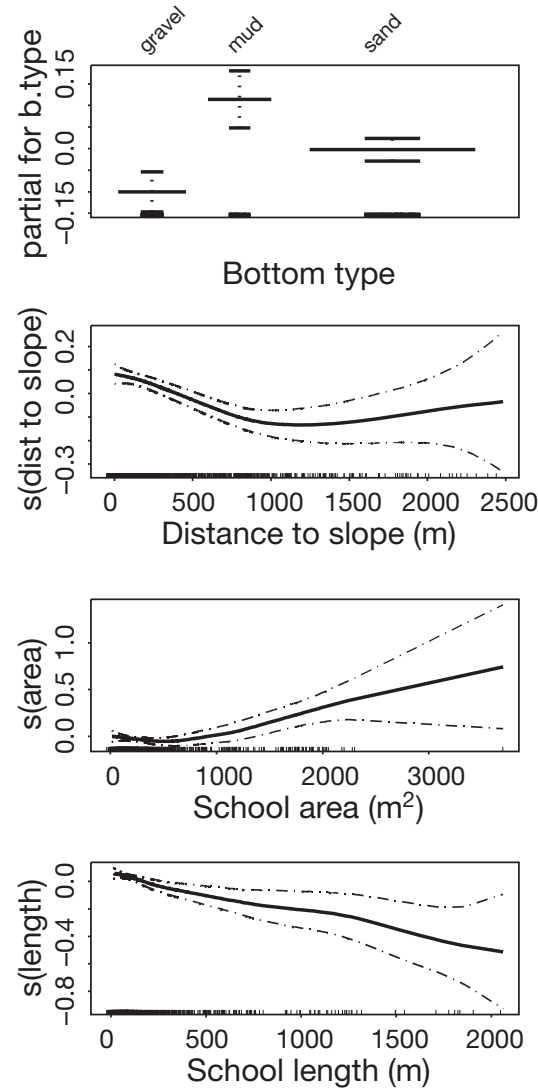

Fig. 7. Generalized additive mixed model (GAMM) plots showing whale behavioral classification as a function of environmental variables and mean school parameters (density, area, height, depth, and length). For each predictor variable, the effect on whale surface feeding likelihood is shown on the $y$-axis and is represented as a spline (s) of the predictor variable. Time of day and tidal height explained most of the variability in foraging, while school density and area were important as well 
sent in the water column during daytime feeding on small zooplankton, while they bury in sandy substrate at night and when they are at low densities, primarily for predator avoidance (Winslade 1974, Meyer et al. 1979, Hobson 1986). In our study, however, sand lance density peaked between 03:00 and 04:00 h (mean sunrise at 05:30 h), but the maximum likelihood of whale surface feeding did not peak until 06:00 h. This suggests that whale foraging did not peak until well after densities of sand lance were substantial enough to be energetically valuable, that the average search time before whales were able to find prey patches was approximately $2 \mathrm{~h}$, or that the whales required sufficient light to be able to use a visually oriented predation strategy (Friedlaender et al. 2009). Further research is necessary during the period from night to dawn in order to understand the mechanisms that trigger behavioral switching in foraging whales.

Acoustic biomass of sand lance was greatest above sandy and mud substrates. While sand lance use the sandy shelf for refuge, mud habitats are most common immediately off the western slope of the bank in deeper waters. In addition, dynamic bathymetry at the slope edge of Stellwagen Bank offers the potential for upwelled productivity with tidal currents (Haury et al. 1979). Tagged whales exhibited surface feeding more often above mud habitats than above sand habitats, but both of these habitats had a higher likelihood of surface feeding than above a gravel bottom. As mud substrate was often found in deeper environments where whales were foraging, it is difficult to tease apart the effect of each of these variables independently.

Although the relationship between sand lance prey density and temperature was significant, the relationship was complex. A general decline in density occurs at the lowest and highest temperatures, although the standard error is particularly high. Low temperatures correspond to nights when sand lance presumably are buried in the substrate, while high temperatures correspond to closer to mid-day when they are dispersed throughout the water column (Meyer et al. 1979). There was a dip in biomass at a surface temperature of $17.5^{\circ} \mathrm{C}$, but the reason for this association is not obvious (Fig. 5). However, despite these relationships, whale surface feeding was not significantly correlated with sea surface temperature (Table 2, Fig. 7).

Both whale surface feeding and prey density showed a negative correlation with surface fluorescence, which is surprising given the proposed bottom-up food web (Meyer et al. 1979). Cascading trophic interactions offer an explanation for this relationship, but tidal aggregation is a more plausible mechanism. Trophic cascades are defined as reciprocal predator-prey effects that alter the abundance, biomass, or productivity of a population community or trophic level across more than one link in a food web (Pace et al. 1999). In this scenario, a high concentration of phytoplankton could result in increased density of small zooplankton that over time would graze down phytoplankton levels. Consequently, increased zooplankton density would attract high densities of sand lance, eventually resulting in increased surface feeding for humpback whales. However, it can take 3 to 4 mo for nutrient upwelling to lead to increased zooplankton densities required by foraging whales (Croll et al. 2005). Cotté \& Simard (2005) focused on a spatio-temporally compact food web in the Laurentian Channel, Canada. Euphausiids (Thysanoessa raschi and Meganyctiphanes norvegica) were aggregated by tidal flow at the edge of the Ile Rouge bank, creating short-lived, high-density prey patches and food webs that build and dissipate up to twice a day. The strong influence of tidal state on Stellwagen Bank suggests that a similar physical aggregation of zooplankton is responsible for increased densities of sand lance and humpback surface feeding.

We used tidal height in our analyses as a proxy for internal wave formation and upwelling. Internal wave packets are generated during ebb tide as a lee wave over the western edge of Stellwagen Bank (Haury et al. 1979). As the tide turns, the waves begin propagating towards shore, and undulations develop as the waves stack up, redistributing chlorophyll and zooplankton (Haury et al. 1979, Stevick et al. 2008). Nonetheless, the high correlation between tidal state and both prey and predator was surprising. Acoustically measured prey were most dense at a tidal height of $\sim 2.4 \mathrm{~m}$, while whale surface feeding peaked at a height of $\sim 3 \mathrm{~m}$ at maximum high tide. This lag suggests that prey are aggregating after the formation of internal waves on the west edge of the bank with a further delay before whales begin surface feeding. The increase in prey distribution and increased observations of whale surface feeding behavior near the slope edge also supports this possibility. Concurrent measurements of internal wave production, propagation, and nutrient upwelling would aid in understanding the influence of such waves on the oceanographic and biological processes of Stellwagen Bank.

Whale surface feeding likelihood was significantly affected by prey school shape. Surface feeding occurred more often around larger schools with a distribution that emphasized the vertical rather than the horizontal. Because humpback whale bubble feeding involves a 'corral' of air bubbles that aggregate prey followed by a feeding lunge through the surface (Jurasz \& Jurasz 1979, Hain et al. 1982), vertically oriented schools could be more easily manipulated by bubbles rising through the water column. Longer (i.e. horizontally oriented) schools were often associated with a thin layer $(<2.5 \mathrm{~m}$ tall $)$ in the water column, 
potentially more difficult or less energetically effective to consume. Although the lack of a clear relationship between dive depth prior to surface feeding and mean school depth defined by the center of the school is surprising, this could be a function of the whale feeding only on a portion of the school, or corralling of deeper schools toward the surface. A more detailed analysis of surface feeding depth relative to both pycnocline depth and mean school height is necessary. Throughout, however, it should be noted that the vessel recording the prey schools was typically at least $200 \mathrm{~m}$ from the tagged whale, suggesting that small-scale variability in prey schools may affect the relationships between whale surface feeding events and the characteristics of the sand lance schools being measured. In addition, because bubble feeding is at times cooperative (e.g. Hain et al. 1982, Baker \& Herman 1984, Weinrich et al. 1991), the tagged whale may not be producing the bubbles, but could be either aiding in corralling behavior or simply taking advantage of another whale's bubble-net. More samples with multiple tags on cooperating foragers will be necessary to better elucidate this relationship.

Predator aggregation most often occurs as a nonlinear function of increasing prey density (Holling 1965, Murdoch \& Oaten 1975), leading to a threshold foraging behavior typical of higher vertebrates (Piatt \& Methven 1992). For balaenopterids, the lower limit is likely set by their metabolic demands combined with their unusual foraging style of engulfing prey (Nagy et al. 1984, Goldbogen et al. 2006). Piatt \& Methven (1992) suggested that because humpback whales have wider jaws and a greater filtering volume for their size than fin or minke whales, they may be able to subsist on lower-density prey aggregations. One of our goals was to measure this threshold for surface-feeding humpback whales. Using GAMM and CART models, we observed that surface feeding was more likely above acoustically detected prey densities of $-65 \mathrm{~dB}$, rejecting our fourth null hypothesis that there were no thresholds in surface-feeding behavior. However, we did not observe a foraging threshold (>-75 dB) below which whales stopped surface feeding. One potential explanation for this difference is that it was difficult to match the distance between the vessel and the exact spatial and temporal location of the feeding whale. Even if exact overlap were possible, bubbles from surface-feeding events would confound the acoustic data, and the research vessel could modify the whale's behavior. Furthermore, these thresholds may vary based on the number of prey patches in an area. More concurrent samples would be necessary to differentiate whether whales preferentially feed on many smaller prey patches or on individual large but spatially distinct patches.
Our ability to understand the decision-making process of a foraging or feeding whale is hampered by a general lack of knowledge of the sensory capabilities of the whales themselves. Humpback whales negotiate their surroundings over spatial scales ranging from $1000 \mathrm{~s}$ of $\mathrm{km}$ (migration routes) to $10 \mathrm{~s}$ of $\mathrm{m}$ (micro-scale feeding on prey patches). Kenney et al. (2001) suggested that while in seasonal foraging areas, North Atlantic right whales sample prey using varied sensory modalities depending upon the distance from the prey. Humpback whales have been observed approaching large-scale prey patches from $10 \mathrm{~s}$ of $\mathrm{km}$ (M. Weinrich unpubl. obs.), suggesting that they too use a variety of senses to make decisions on varying ecological scales. Including net tows in future studies would provide additional validation of prey species and would allow us to include the effect of prey length on feeding thresholds.

Our research provides a finer-scale analysis of baleen whale predatory behavior relative to their prey and a suite of environmental variables, and has allowed us to discover possible cues that the whales themselves may use for foraging. In addition, we were able to identify an upper threshold of relative prey density above which surface-feeding likelihood only minimally increased. Daylight hours, high tidal heights, and prey distribution were good predictors of whale surface feeding. This understanding of whale foraging behavior at the scale of an individual whale is an important addition to our ecological understanding of baleen whales and their relationship to marine ecosystems.

Acknowledgements. We thank Dr. J. M. Jech and J. Condiotty for use of and help with the EK60 echosounders and processing software. We also thank the scientific crew, particularly K. Sardi and C. Pecarcik of the Whale Center of New England, R. Arsenault of the University of New Hampshire, A. Stimpert of the University of Hawaii, and the NOAA crew aboard the RV 'Nancy Foster' for their help with gear deployment, gear fabrication, and data collection. The Stellwagen Bank National Marine Sanctuary office offered both funding and logistical support to aid in the collection and analysis of this research. Whale tag data were collected under MMPA permit \#775-1875. The manuscript was improved thanks to comments from 2 anonymous reviewers and the editors.

\section{LITERATURE CITED}

Anthony VC, Waring G (1980) The assessment and management of the Georges Bank herring fishery. Rapp Cons Int Explor Mer 177:72-111

Auster P, Joy K, Valentine P (2001) Fish species and community distributions as proxies for seafloor habitat distributions: the Stellwagen Bank National Marine Sanctuary example. Environ Biol Fishes 60:331-346

Baker CS, Herman LM (1984) Seasonal contrasts in the social 
behavior of humpback whales. Cetus 5:14-16

Baumgartner MF, Cole TVN, Campbell RG, Teegarden GJ, Durbin EG (2003) Associations between North Atlantic right whales and their prey, Calanus finmarchicus, over diel and tidal time scales. Mar Ecol Prog Ser 264:155-166

Benoit-Bird KJ, Au WWL, Brainard RE, Lammers MO (2001) Diel horizontal migration of the Hawaiian mesopelagic boundary community observed acoustically. Mar Ecol Prog Ser 217:1-14

Charnov EL (1976) Optimal foraging: the marginal value theorem. Theor Popul Biol 9:129-136

- Clapham PJ, Baraff LS, Carlson CA, Christian MA and others (1993) Seasonal occurrence and annual return of humpback whales, Megaptera novaeangliae, in the southern Gulf of Maine. Can J Zool 71:440-443

> Coetzee J (2000) Use of a shoal analysis and patch estimation system (SHAPES) to characterize sardine schools. Aquat Living Resour 13:1-10

Cotté C, Simard Y (2005) Formation of dense krill patches under tidal forcing at whale feeding hot spots in the St. Lawrence Estuary. Mar Ecol Prog Ser 288:199-210

Croll DA, Tershy BR, Hewitt RP, Demer DA and others (1998) An integrated approach to the foraging ecology of marine birds and mammals. Deep-Sea Res II 45:1353-1371

Croll DA, Marinovic B, Benson S, Chavez FP, Black N, Ternullo R, Tershy BR (2005) From wind to whales: trophic links in a coastal upwelling system. Mar Ecol Prog Ser 289:117-130

> Demer D, Soule MA, Hewitt RP (1999) A multiple-frequency method for potentially improving the accuracy and precision of in situ target strength measurements. J Acoust Soc Am 105:2359-2376

Dolphin WF (1987) Prey densities and foraging of humpback whales, Megaptera novaeangliae. Experientia 43:468-471

Fauchald P, Erikstad KE, Skarsfjord H (2000) Scale-dependent predator-prey interactions: the hierarchical spatial distribution of seabirds and prey. Ecology 81:773-783

Fogarty MJ, Murawski SA (1998) Large-scale disturbance and the structure of marine systems: fishery impacts on Georges Bank. Ecol Appl 8:S6-S22

Freeman S, Mackinson S, Flatt R (2004) Diel patterns in the habitat utilisation of sandeels revealed using integrated acoustic surveys. J Exp Mar Bio Ecol 305:141-154

Friedlaender AS, Halpin PN, Qian SS, Lawson GL, Wiebe PH, Thiele D, Read AJ (2006) Whale distribution in relation to prey abundance and oceanographic processes in shelf waters of the Western Antarctic Peninsula. Mar Ecol Prog Ser 317:297-310

Friedlaender AS, Hazen EL, Nowacek DP, Halpin PN and others (2009) Diel changes in humpback whale Megaptera novaeangliae feeding behavior in response to sand lance Ammodytes spp. behavior and distribution. Mar Ecol Prog Ser 395:91-100

Garrison LP (2000) Spatial and dietary overlap in the Georges Bank groundfish community. Can J Fish Aquat Sci 57:1679-1691

Gaskin DE (1982) The ecology of whales and dolphins. Heinemann, London

Gauthier S, Horne JK (2004) Acoustic characteristics of forage fish species in the Gulf of Alaska and Bering Sea based on Kirchhoff-approximation models. Can J Fish Aquat Sci 61: 1839-1850

Goldbogen JA, Calambokidis J, Shadwick RE, Oleson EM, McDonald MA, Hildebrand JA (2006) Kinematics of foraging dives and lunge-feeding in fin whales. J Exp Biol 209: 1231-1244

Hain JHW, Carter GR, Kraus SD, Mayo CA, Winn HE (1982)
Feeding behavior of the humpback whale, Megaptera novaeangliae, in the western North Atlantic. Fish Bull (Wash DC) 80:259-268

> Hain JHW, Ellis SL, Kenney RD, Clapham PJ, Gray BK, Weinrich MT, Babb IG (1995) Apparent bottom feeding by humpback whales on Stellwagen Bank. Mar Mamm Sci 11:464-479

Harley SJ, Myers RA (2001) Hierarchical Bayesian models of length-specific catchability of research trawl surveys. Can J Fish Aquat Sci 58:1569-1584

> Haury LR, Briscoe MG, Orr MH (1979) Tidally generated internal wave packets in Massachusetts Bay. Nature 278:312-317

> Hays HE, Winn HE, Petricig R (1985) Anomalous feeding behavior of a humpback whale. J Mammal 66:819-821

Hobson ES (1986) Predation on the Pacific sand lance Ammodytes hexapterus (Pisces: Ammodytidae), during the transition between day and night in southeastern Alaska. Copeia 1986:223-226

Holling CS (1965) The functional response of predators to prey density and its role in mimicry and population regulation. Mem Entomol Soc Can 45:1-60

Johnson MP, Tyack PL (2003) A digital acoustic recording tag for measuring the response of wild marine mammals to sound. IEEE J Ocean Eng 28:3-12

Johnston DW, Westgate AJ, Read AJ (2005a) Effects of fine scale oceanographic features on the distribution and movements of harbour porpoises Phocoena phocoena in the Bay of Fundy. Mar Ecol Prog Ser 295:279-293

Johnston DW, Thorne LH, Read AJ (2005b) Fin whales Balaenoptera physalus and minke whales Balaenoptera acutorostrata exploit a tidally driven island wake ecosystem in the Bay of Fundy. Mar Ecol Prog Ser 305:287-295

Jurasz C, Jurasz V (1979) Feeding modes of the humpback whale Megaptera novaeangliae in southeast Alaska. Sci Rep Whale Res Inst 31:69-83

Kenney RD, Mayo CA, Winn HE (2001) Migration and foraging strategies at varying spatial scales in western North Atlantic right whales: a review of hypotheses. J Cetacean Res Manag 2:251-260

Lennert-Cody CE, Franks PJS (1999) Plankton patchiness in high-frequency internal waves. Mar Ecol Prog Ser 186: 59-66

Levin SA (1992) The problem of pattern and scale in ecology. Ecology 73:1943-1976

MacArthur RH, Pianka ER (1966) On optimal use of a patchy environment. Am Nat 100:603-609

> Mackinson S, Nøttestad L, Guenette S, Pitcher T, Misund OA, Fernö A (1999) Cross-scale observations on distribution and behavioural dynamics of ocean feeding Norwegian spring-spawning herring (Clupea harengus L.). ICES J Mar Sci 56:613-626

> Maravelias CD, Reid DG, Simmonds EJ, Haralabous J (1996) Spatial analysis and mapping of acoustic survey data in the presence of high local variability: geostatistical application to North Sea herring (Clupea harengus). Can J Fish Aquat Sci 53:1497-1505

Mayo CA, Marx MK (1990) Surface foraging behavior of the North Atlantic right whale, Eubalaena glacialis, and associated zooplankton characteristics. Can J Zool 68: $2214-2220$

Meyer TL, Cooper RA, Langton RW (1979) Relative abundance, behavior, and food habitats of the American sand lance, Ammodytes americanus, from the Gulf of Maine. Fish Bull (Wash DC) 77:243-253

> Miller PJO, Johnson MP, Tyack PL, Terray EA (2004a) Swimming gaits, passive drag, and buoyancy of diving sperm 
whales (Physeter macrocephalus). J Exp Biol 207: 1953-1967

Misund OA, Fernö A, Pitcher T, Totland B (1998) Tracking herring schools with a high resolution sonar. Variations in horizontal area and relative echointensity. ICES J Mar Sci 55:58-66

$>$ Murdoch WW, Oaten A, (1975) Predation and population stability. Adv Ecol Res 9:1-131

Nagy KA, Huey RB, Bennett AF (1984) Field energetics and foraging mode of Kalahari lacertid lizards. Ecology 65: 588-596

> Nøttestad L, Fernö A, Pitcher T, Mackinson S, Misund OA (2002) How whales influence herring school dynamics in a cold front area in the Norwegian Sea. ICES J Mar Sci 59:393-400

> Nowacek DP, Johnson MP, Tyack PL (2004) North Atlantic right whales (Eubalaena glacialis) ignore ships but respond to alerting stimuli. Proc R Soc Lond B Biol Sci 271:227-231

> Overholtz WJ (2002) The Gulf of Maine-Georges Bank Atlantic herring (Clupea harengus): spatial pattern analysis of the collapse and recovery of a large marine fish complex. Fish Res 57:237-254

Overholtz WJ, Nicolas JR (1979) Apparent feeding of the fin whale, Balaenoptera physalus, and the humpback whale, Megaptera novaeangliae, on the American sand lance, Ammodytes americanus, in the northwest Atlantic. Fish Bull (Wash DC) 77:285-287

Pace ML, Cole JJ, Carpenter SR, Kitchell JF (1999) Trophic cascades revealed in diverse ecosystems. Trends Ecol Evol $14: 483-488$

Payne PM, Nicolas JR, O'Brien L, Powers KD (1986) The distribution of the humpback whale, Megaptera novaeangliae, on Georges Bank and in the Gulf of Maine in relation to densities of the sand eel, Ammodytes americanus. Fish Bull (Wash DC) 84:271-277

Payne PM, Wiley D, Young S, Pittman S, Clapham PJ, Jossi JW (1990) Recent fluctuations in the abundance of baleen whales in the southern Gulf of Maine in relation to changes in prey abundance. Fish Bull (Wash DC) 88: 687-696

Petitgas P (1993) Geostatistics for fish stock assessments: a review and an acoustic application. ICES J Mar Sci 50: 285-298

Piatt JF (1990) The aggregative response of common murres and Atlantic puffins to schools of capelin. Stud Avian Biol 14:36-51

Piatt JF, Methven DA (1992) Threshold foraging behavior of baleen whales. Mar Ecol Prog Ser 84:205-210

Pittman S, Costa B, Kot C, Wiley D, Kenney RD (2006) Cetacean distribution and diversity. In: Battista T, Clark R, Pittman S (eds) An ecological characterization of the Stellwagen Bank National Marine Sanctuary Region: oceanographic, biogeographic, and contaminants assessment. NOAA Tech Memo NOS NCCOS 45. National Oceanic and Atmospheric Administration, National Ocean Service, National Centers for Coastal Ocean Science, Center for Coastal Monitoring and Assessment, Silver Spring, MD, p 264-324

Redfern JV, Ferguson MC, Becker EA, Hyrenbach KD and others (2006) Techniques for cetacean-habitat modeling. Mar Ecol Prog Ser 310:271-295

Robinson AR, Lermusiaux PFJ (2002) Data assimilation for modeling and predicting coupled physical-biological interactions in the sea. In: Robinson AR, McCarthy JJ, Rothschild BJ (eds) The sea, Vol 12. Wiley, New York, p 475-536

Simmonds EJ, MacLennan DN (2005) Fisheries acoustics: theory and practice, Vol 2. Blackwell Science, Oxford

Stevick PT, Allen J, Clapham PJ, Katona SK and others (2006) Population spatial structuring on the feeding grounds in North Atlantic humpback whales (Megaptera novaeangliae). J Zool (Lond) 270:244-255

Stevick PT, Incze LS, Kraus SD, Rosen S, Wolff N, Baukus A (2008) Trophic relationships and oceanography on and around a small offshore bank. Mar Ecol Prog Ser 363: $15-28$

> Thiele DC, Chester ET, Moore SE, Sirovic A, Hildebrand JA, Friedlaender AS (2004) Seasonal variability in whale encounters in the Western Antarctic Peninsula. Deep-Sea Res II 51:2311-2325

> Ware CR, Arsenault R, Plumlee M, Wiley D (2006) Visualizing the underwater behavior of humpback whales. IEEE Comput Graph Appl 26:14-18

Warren JD, Stanton TK, Wiebe PH, Seim HE (2003) Inference of biological and physical parameters in an internal wave using multiple-frequency, acoustic-scattering data. ICES J Mar Sci 60:1033-1046

> Watkins WA, Schevill WE (1979) Aerial observation of feeding in four baleen whales: Eubalaena glacialis, Balaenoptera borealis, Megaptera novaeangliae, and Balaenoptera physalus. J Mammal 60:155-163

> Weinrich MT (1998) Early experience in habitat choice by humpback whales (Megaptera novaeangliae). J Mammal 79:163-170

> Weinrich MT, Kuhlberg AK (1991) Short-term association patterns of humpback whale (Megaptera novaeangliae) groups on their southern Gulf of Maine feeding ground. Can J Zool 69:3005-3011

Weinrich MT, Lambertson RH, Belt CR, Schilling MR, Iken HJ, Syrjala SE (1992a) Behavioral reactions of humpback whales Megaptera novaeangliae to biopsy procedures. Fish Bull (Wash DC) 90:588-598

Weinrich MT, Schilling MR, Belt CR (1992b) Evidence for acquisition of a novel feeding behavior: lobtail feeding in humpback whales, Megaptera novaeangliae. Anim Behav 44:1059-1072

Weinrich MT, Martin M, Griffiths R, Bove J, Schilling M (1997) A shift in distribution of humpback whales, Megaptera novaeangliae, in response to prey in the southern Gulf of Maine. Fish Bull (Wash DC) 95:826-836

Whitehead HP (1983) Structure and stability of humpback whale groups off Newfoundland. Can J Zool 61: 1391-1397

Whitehead HP, Carscadden JE (1985) Predicting inshore whale abundance: whales and capelin off the Newfoundland coast. Can J Fish Aquat Sci 42:976-981

> Winslade PR (1974) Behavioural studies on the lesser sandeel Ammodytes marinus (Raitt) II. The effect of food availability on activity and the role of olfaction in food detection. J Fish Biol 6:565-576

Witteveen BH, Foy RJ, Wynne KM, Tremblay Y (2008) Investigation of foraging habits and prey preference of humpback whales (Megaptera novaeangliae) near Kodiak Island, Alaska using acoustic tags. Mar Mamm Sci 24:516-534

Wood S (2006) Generalized additive models. An introduction with R. Chapman \& Hall, London

Proofs received from author(s): July 9, 2009 